\title{
Organizational Contact Primary Indicator
}

National Cancer Institute

\section{Source}

National Cancer Institute. Organizational Contact Primary Indicator. NCI Thesaurus.

Code C93881.

Specifies whether this is the main or principal organizational contact. 